\title{
PRODUCTION ANALYSIS OF A TUBULAR SOLAR STILL
}

\author{
Kh. Md. Shafiul ISLAM ${ }^{1}$ and Teruyuki FUKUHARA ${ }^{2}$ \\ ${ }^{1}$ Student Member of JSCE, PhD Student, Dept. of Architecture and Civil Engineering, University of Fukui \\ (3-9-1 Bunkyo, Fukui 910-8507, Japan) \\ E-mail:khmsislam@yahoo.com \\ ${ }^{2}$ Member of JSCE, Professor, Dept. of Architecture and Civil Engineering, University of Fukui \\ (3-9-1 Bunkyo, Fukui 910-8507, Japan) \\ E-mail:teruyuki@anc.anc-d.fukui-u.ac.jp
}

\begin{abstract}
In this study, attempts were made to provide a group of complete heat and mass transfer correlations, and to propose a new heat and mass transfer model for a Tubular Solar Still (TSS) by taking account of thermal properties of the humid air inside the still. We developed a new experimental technique for directly measuring the evaporation rate from the saline water surface in the TSS and evaluated the evaporative mass transfer coefficient. Indoor experiments were conducted to investigate the production performance and the heat and mass transfer coefficients of the TSS. It was found that i) the heat and mass transfer coefficients, $h_{c h a}, h_{c w}, h_{c d h a}, h_{e w}$ can be expressed as functions of the temperature difference between the saline water and the cover, and ii) the conventional formula available for a basin type still overestimates the convective heat transfer coefficient, $h_{c w}$ for the TSS. Furthermore, in this study, the long-wave radiation interaction between the water surface and the tubular cover was shown theoretically.

We also proposed a new heat and mass transfer model of TSS. The mass balance of water vapor inside the still was formulized for the first time. The proposed model was successful in the calculation of humid air properties (temperature, vapor density and relative humidity) and condensation flux on the tubular cover inner surface besides the saline water temperature, tubular cover temperature, trough temperature and evaporation flux. The validity of the model was evaluated from the comparison with field experiments in Fukui, Japan and in Hamuraniyah, UAE. It was seen that the calculated results also had a good agreement with the field data.
\end{abstract}

Key Words : condensation, convection, evaporation, heat and mass transfer coefficient, humid air, production, radiation, trough, Tubular Solar Still (TSS)

\section{INTRODUCTION}

The human and economic activities, particularly in arid and remote areas, may depend on desalination performance to meet fresh water demand produced from brackish or saline water. Solar distillation is the simplest desalination technique, compared with other methods, e.g., multiple-effect distillation, multi-stage flash, reverse osmosis, electro-dialysis and biological treatment. The main disadvantage of solar distillation is its low productivity of distillate, although it may also be one of the viable options for providing drinking water for a single house or a small community in arid regions. A basin-type solar still is the most popular method of solar distillation, but main drawbacks of the basin type are not easy to construct and have the difficulty in rapid and easy removal of basin accumulated salt.
Therefore, we designed a new type of solar distillation, Tubular Solar Still (TSS), to overcome such difficulties in maintenance and management. The TSS consists of a trough and a tubular cover and has been undergoing tests (along with the basin type still) in the United Arab Emirates (UAE) since 2001.

For better understanding of the production mechanism and to improve the performance of a solar still, it is important to accurately know the heat and mass transfer processes in it. In this regard, many researchers $\left(\mathrm{Chaibi}^{1)}\right.$, Clark $^{2)}$, Cooper ${ }^{3)}$, Dunkle ${ }^{4)}$, Hongfei et al. ${ }^{5)}$, Malik et al. ${ }^{6}$, Shawaqfeh and Farid $^{7)}$ ) have mainly conducted experimental and theoretical studies on conventional basin type still rather than other types such as tubular still. They also proposed a numerous heat and mass transfer correlations in terms of the temperature and 
vapor pressure or density on saline water surface and still over, neglecting the existence of intermediate medium between the two, i.e., humid air. In 1961, Dunkle ${ }^{4)}$ first proposed a group of complete heat and mass transfer correlations based on a special Grashof number for basin type solar still. He proposed an empirical equation for convective heat transfer coefficient, $h_{c w}$ and derived a theoretical relation for evaporative heat flux, $q_{e w}$ given by Equations (1) and (2), respectively.

$$
\begin{gathered}
h_{c w}=0.884\left[T_{w}-T_{c}+\frac{\left(P_{v w}-P_{v c}\right)\left(T_{w}+273\right)}{\left(268.9 \times 10^{3}-P_{v w}\right)}\right]^{\frac{1}{3}} \\
q_{e w}=16.273 \times 10^{-3} h_{c w}\left(P_{v w}-P_{v c}\right)
\end{gathered}
$$

where, $P_{v w}$ and $P_{v c}$ are the partial pressure of water vapors at saline water temperature, $T_{w}$, and cover temperature, $T_{c}$, respectively $\left(\mathrm{N} / \mathrm{m}^{2}\right)$. The correlations proposed by Dunkle ${ }^{4}$ have been the most popular ones and widely used by almost all researchers for analysis of basin type still. Unfortunately, no correlations have been developed for other types such as tubular solar still. For example, Kumar and Anand ${ }^{8)}$ and Tiwari and Kumar ${ }^{9)}$ used the correlations (Equations (1) and (2)) for analysis of the performance of a multiwick tubular solar still and a tubular solar still, respectively.

Nagai et al. ${ }^{10)}$ and Islam and Fukuhara ${ }^{11)}$, however, found that the relative humidity of humid air is by no means saturated in the daytime and proposed a new model incorporated the heat transfer in the humid air. The production mechanism along with heat and mass transfer coefficients of solar stills can be judged more preciously under steady meteorological condition and the results can be applied to portray a more accurate unsteady production model.

Therefore, first we created a new experimental technique for directly measuring the evaporation rate from the saline water surface in the TSS. Then indoor experiments were conducted for the purpose of formulating the heat and mass transfer coefficients.

A new concept of heat and mass transfer model was also developed to explain the unsaturated water vapor in the TSS and to calculate the condensation flux on the tubular cover inner surface in this study.

This paper aims to propose the new heat and mass transfer model for a TSS taking account of the thermal properties of humid air and verify the validity of the model.

\section{THEORY OF HEAT AND MASS TRANSFER IN A TSS}

\section{(1) New points of the proposed model}

Table 1 shows the differences between the proposed model and the past model. The former incorporated new heat and mass balance equations of the humid air in the later, shown in the lower half of the table. As a result, the proposed model made it possible to calculate the humid air properties (temperature, vapor density and relative humidity) and condensation flux besides the saline water temperature, tubular cover temperature, trough temperature and evaporation flux.

\section{(2) Model assumptions}

The mass and energy balance equations are made up on the following assumptions:

i) Heat and mass transfer in a TSS are formalized using the representative temperature of the saline water, humid air, trough and tubular cover and the relative humidity of the humid air.

ii) Water vapor on the water surface is saturated.

iii) There is no water vapor leakage across the tubular cover.

iv) The absorption of the solar radiation in the humid air is negligibly small.

Fig. 1 shows the mass and energy transfer within and outside a TSS. The key point of modeling is the accuracy of the evaporation from the saline water surface and the condensation on the tubular cover.

\section{(3) Mass balance equations \\ a) Saline water in a trough}

The mass of the saline water in a trough is prescribed by the evaporation from the saline water surface and the time rate of the mass reduction is written as:

\begin{tabular}{|c|c|c|c|c|}
\hline \multirow{2}{*}{\multicolumn{2}{|c|}{ Model }} & \multicolumn{2}{|c|}{ Theory } & \multirow{2}{*}{ Output } \\
\hline & & Mass balance & Heat balance & \\
\hline \multirow{2}{*}{ Proposed } & Past & - Saline water & $\begin{array}{l}\text { - Saline water } \\
\text { - Cover } \\
\text { - Trough }\end{array}$ & $\begin{array}{l}\text { - Saline water temperature } \\
\text { - Cover temperature } \\
\text { - Trough temperature } \\
\text { - Evaporation mass flux }\end{array}$ \\
\hline & & - Water vapor in humid air & - Humid air & $\begin{array}{l}\text { - Humid air temperature } \\
\text { - Humid air vapor density } \\
\text { - Humid air relative humidity } \\
\text { - Condensation mass flux }\end{array}$ \\
\hline
\end{tabular}

Table 1 Differences between the proposed model and the past model. 


$$
\frac{d V_{w}}{d t}=-\frac{m_{\text {evap }} A_{w}}{\rho_{w}}
$$

where, $V_{w}$ is the volume of water in a trough $\left(\mathrm{m}^{3}\right)$, $A_{w}$ is the water surface area $\left(\mathrm{m}^{2}\right), m_{\text {evap }}$ is the evaporation flux $\left(\mathrm{kg} / \mathrm{m}^{2} \mathrm{~s}\right), \rho_{w}$ is the density of water $\left(\mathrm{kg} / \mathrm{m}^{3}\right)$ and $t$ is time (s).

\section{b) Water vapor in humid air}

The mass balance of water vapor in humid air can be expressed as:

$$
\begin{aligned}
V_{h a} \frac{\partial \rho_{\text {vha }}}{\partial t} & =M_{\text {evap }}-M_{\text {cond }} \\
& =A_{w} m_{\text {evap }}-A_{c} m_{\text {cond }}
\end{aligned}
$$

where, $V_{h a}$ is the volume of humid air $\left(\mathrm{m}^{3}\right), \rho_{v h a}$ is the vapor density of the humid air $\left(\mathrm{kg} / \mathrm{m}^{3}\right), M_{\text {evap }}$ is the evaporation $(\mathrm{kg} / \mathrm{s}), M_{\text {cond }}$ is the condensation on the inner surface of the tubular cover $(\mathrm{kg} / \mathrm{s}), A_{c}$ is the tubular cover surface area $\left(\mathrm{m}^{2}\right)$ and $m_{\text {cond }}$ is the condensation flux $\left(\mathrm{kg} / \mathrm{m}^{2} \mathrm{~s}\right) . m_{\text {evap }}$ and $m_{\text {cond }}$ may be calculated from the following equations, respectively.

$$
\begin{aligned}
& m_{\text {evap }}=h_{e w}\left(\rho_{v w}-\rho_{v h a}\right) \\
& m_{\text {cond }}=h_{c d h a}\left(\rho_{v h a}-\rho_{v c}\right)
\end{aligned}
$$

where, $h_{e w}$ is the evaporative mass transfer coefficient $(\mathrm{m} / \mathrm{s}), h_{\text {cdha }}$ is the condensative mass transfer coefficient $(\mathrm{m} / \mathrm{s}), \rho_{v w}$ is the vapor density on the saline water surface $\left(\mathrm{kg} / \mathrm{m}^{3}\right)$ and $\rho_{v c}$ is the vapor density on the tubular cover $\left(\mathrm{kg} / \mathrm{m}^{3}\right)$.

\section{(4) Energy balance equations}

The energy balance equations of the TSS may be expressed as follows:

Saline water:

$$
(\rho C)_{w} \frac{\partial\left(V_{w} T_{w}\right)}{\partial t}=R_{w}+Q_{t w}-Q_{e w}-Q_{c w}-Q_{r w}
$$

Trough:

$$
(\rho C V)_{t} \frac{\partial T_{t}}{\partial t}=R_{t}-Q_{t w}-Q_{t h a}
$$

Humid air:

$$
\begin{aligned}
& (\rho C V)_{h a} \frac{\partial T_{h a}}{\partial t}= \\
& R_{h a}+Q_{e w}+Q_{c w}+Q_{t h a}-Q_{c h a}-Q_{c d h a}
\end{aligned}
$$

Tubular cover:

$$
\begin{aligned}
& (\rho C V)_{c} \frac{\partial T_{c}}{\partial t}= \\
& R_{c}+Q_{c h a}+Q_{c d h a}+Q_{r w}-Q_{c c}-Q_{r c}
\end{aligned}
$$

where,

$$
\begin{aligned}
& Q_{c c}=h_{c c}\left(T_{c}-T_{a}\right) A_{c} \\
& Q_{c d h a}=\operatorname{Lh} c d h a\left(\rho_{v h a}-\rho_{v c}\right) A_{c} \\
& Q_{c h a}=h_{c h a}\left(T_{h a}-T_{c}\right) A_{c} \\
& Q_{c w}=h_{c w}\left(T_{w}-T_{h a}\right) A_{w} \\
& Q_{e w}=L_{e w}\left(\rho_{v w}-\rho_{v h a}\right) A_{w} \\
& Q_{r c}=h_{r c}\left(T_{c}-T_{a}\right) A_{c}
\end{aligned}
$$

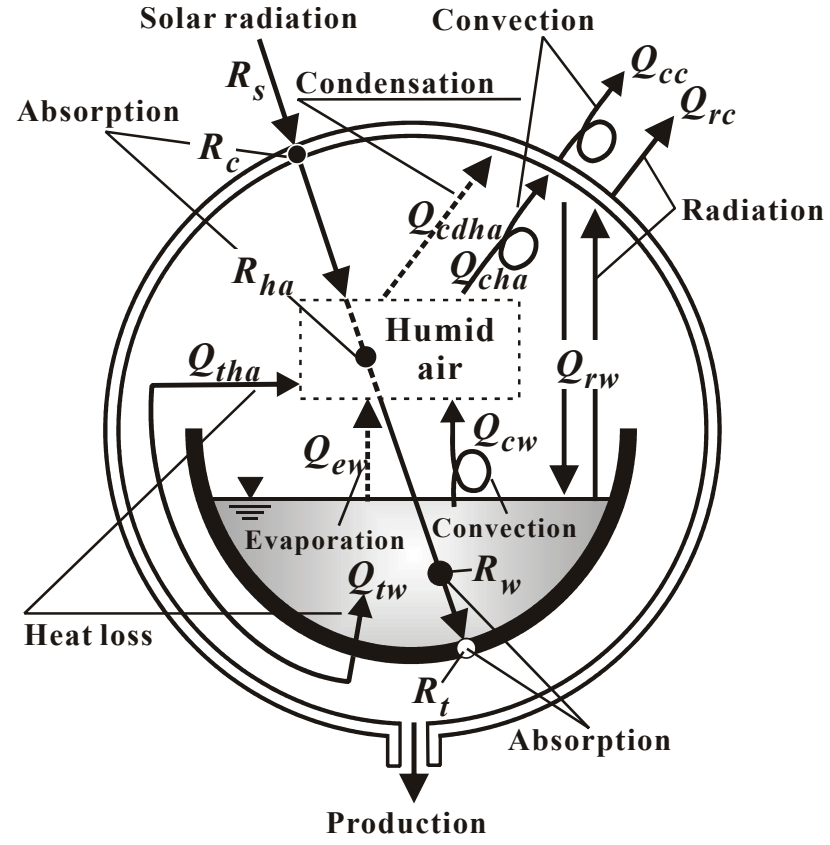

Fig. 1 Mass and energy transfer within and outside of a TSS.

$$
\begin{aligned}
Q_{r w} & =h_{r w}\left(T_{w}-T_{c}\right) A_{w} \\
Q_{t h a} & =h_{t h a}\left(T_{t}-T_{h a}\right) A_{t h a} \\
Q_{t w} & =h_{t w}\left(T_{t}-T_{w}\right) A_{t w} \\
R_{t} & =\tau_{t 1} R_{s} A_{w}+\tau_{t 2} R_{s}\left(2 r_{t} l_{t}-A_{w}\right) \\
R_{c} & =2 \tau_{c} R_{s} r_{c} \\
R_{h a} & =\tau_{h a} R_{s} A_{h a} \\
R_{w} & =\tau_{w} R_{s} A_{w} \\
\tau_{c} & =\left(1-a l_{c}\right) \alpha_{c} \\
\tau_{h a} & =\left(1-a l_{c}\right)\left(1-\alpha_{c}\right) \alpha_{h a} \\
\tau_{t 1} & =\left(1-a l_{c}\right)\left(1-\alpha_{c}\right)\left(1-\alpha_{h a}\right)\left(1-a l_{w}\right)\left(1-\alpha_{w}\right)\left(1-a l_{t}\right) \alpha_{t} \\
\tau_{t 2} & =\left(1-a l_{c}\right)\left(1-\alpha_{c}\right)\left(1-\alpha_{h a}\right)\left(1-a l_{t}\right) \alpha_{t} \\
\tau_{w} & =\left(1-a l_{c}\right)\left(1-\alpha_{c}\right)\left(1-\alpha_{h a}\right)\left(1-a l_{w}\right) \alpha_{w}
\end{aligned}
$$

in which,

$$
A \quad: \text { area }\left(\mathrm{m}^{2}\right)
$$

$A_{\text {tha }}$ : contact surface area between trough and humid air $\left(\mathrm{m}^{2}\right)$

$A_{t w}$ : contact surface area between trough and water $\left(\mathrm{m}^{2}\right)$

al : albedo (-)

$C \quad$ : specific heat capacity $\quad\left(\mathrm{J} / \mathrm{kg}^{\circ} \mathrm{C}\right)$

$h_{c c}$ : convective heat transfer coefficient between tubular cover and atmosphere $\left(\mathrm{W} / \mathrm{m}^{2}{ }^{\circ} \mathrm{C}\right)$

$h_{\text {cdha }}:$ condensative mass transfer coefficient from humid air to tubular cover $\quad(\mathrm{m} / \mathrm{s})$

$h_{\text {cha }}$ : convective heat transfer coefficient between humid air and tubular cover $\quad\left(\mathrm{W} / \mathrm{m}^{2}{ }^{\circ} \mathrm{C}\right)$

$h_{c w}:$ convective heat transfer coefficient between water surface and humid air $\quad\left(\mathrm{W} / \mathrm{m}^{2}{ }^{\circ} \mathrm{C}\right)$

$h_{e w}:$ evaporative mass transfer coefficient from water surface to humid air $\quad(\mathrm{m} / \mathrm{s})$

$h_{r c}$ : radiative heat transfer coefficient between tubular cover and sky $\quad\left(\mathrm{W} / \mathrm{m}^{2}{ }^{\circ} \mathrm{C}\right)$

$h_{r w}$ : radiative heat transfer coefficient between water surface and tubular cover $\left(\mathrm{W} / \mathrm{m}^{2}{ }^{\circ} \mathrm{C}\right)$

$h_{\text {tha }}:$ convective heat transfer coefficient between trough and humid air $\quad\left(\mathrm{W} / \mathrm{m}^{2}{ }^{\circ} \mathrm{C}\right)$ 
$h_{t w}:$ convective heat transfer coefficient between trough and water

$\left(\mathrm{W} / \mathrm{m}^{2}{ }^{\circ} \mathrm{C}\right)$

$l \quad:$ length

$L \quad:$ latent heat of vaporization $\quad(\mathrm{J} / \mathrm{kg})$

$Q_{c c}$ : convective heat flow between tubular cover and atmosphere

$(\mathrm{J} / \mathrm{s})$

$Q_{c d h a}:$ condensative heat flow from humid air to tubular cover

$Q_{c h a}:$ convective heat flow between humid air and tubular cover

$Q_{c w}$ : convective heat flow between water surface and humid air

$Q_{e w}:$ evaporative heat flow from water surface to humid air

$Q_{r c}:$ radiative heat flow between tubular cover and sky

$(\mathrm{J} / \mathrm{s})$

$Q_{r w}$ : radiative heat flow between water surface and tubular cover

$Q_{\text {tha }}:$ convective heat flow between trough and humid air

$Q_{t w}$ : convective heat flow between trough and water

$(\mathrm{J} / \mathrm{s})$

$r \quad:$ radius

$R_{s} \quad:$ solar radiation flux

$\left(\mathrm{W} / \mathrm{m}^{2}\right)$

$R_{c} \quad:$ solar energy absorbed by cover $(\mathrm{J} / \mathrm{s})$

$R_{h a}:$ solar energy absorbed by humid air

$R_{t} \quad$ : solar energy absorbed by trough

$R_{w} \quad:$ solar energy absorbed by water $(\mathrm{J} / \mathrm{s})$

$T:$ : temperature

$\left(\mathrm{m}^{3}\right)$

$\begin{array}{lll}\alpha & : \text { absorption coefficient } & (-) \\ \rho & : \text { density } & \left(\mathrm{kg} / \mathrm{m}^{3}\right)\end{array}$

The subscripts $a, c, h a, t$ and $w$ denote atmosphere, tubular cover, humid air, trough and saline water, respectively. The inclination of the solar radiation and the sunshade effect of the trough are taken account into the value of $R_{s}$.

\section{(5) Modeling and its solution}

Equation (7) can be written as;

$$
\begin{aligned}
(\rho C)_{w} & {\left[V_{w} \frac{\partial T_{w}}{\partial t}+T_{w} \frac{\partial V_{w}}{\partial t}\right] } \\
& =R_{w}+Q_{t w}-Q_{e w}-Q_{c w}-Q_{r w}
\end{aligned}
$$

Inserting Equation (3) into the second term of the left hand side of Equation (11) yields;

$$
\begin{aligned}
& (\rho C)_{w} V_{w} \frac{\partial T_{w}}{\partial t} \\
& \quad=R_{w}+Q_{t w}-Q_{e w}-Q_{c w}-Q_{r w}+(\rho C)_{w} T_{w} \frac{m_{e} A_{w}}{\rho_{w}} \\
& =\Delta Q_{w}
\end{aligned}
$$

where,

$$
\begin{aligned}
\Delta Q_{w}= & R_{w}+Q_{t w}-Q_{e w}-Q_{c w}-Q_{r w} \\
& +(\rho C)_{w} T_{w} \frac{m_{e} A_{w}}{\rho_{w}}
\end{aligned}
$$

An explicit finite difference scheme can be used to discretize the basic equations (4) and (7) to (10). Thus, $T_{w}$ is simply given at each time step by the following equation, i.e.,

$$
T_{w}^{n+1}=T_{w}^{n}+\frac{\left(\Delta Q_{w}\right)^{n} \Delta t}{(\rho C)_{w} V_{w}^{n}}
$$

where, $\Delta t$ is the time increment (s) and $n$ is the time step.

Similarly, the time change of $T_{t}, T_{h a}, T_{c}$ and $\rho_{v h a}$ can be computed by the following discretized equations, respectively.

$$
\begin{gathered}
T_{t}^{n+1}=T_{t}^{n}+\frac{\left(\Delta Q_{t}\right)^{n} \Delta t}{(\rho C V)_{t}} \\
T_{h a}^{n+1}=T_{h a}^{n}+\frac{\left(\Delta Q_{h a}\right)^{n} \Delta t}{(\rho C V)_{h a}} \\
T_{c}^{n+1}=T_{c}^{n}+\frac{\left(\Delta Q_{c}\right)^{n} \Delta t}{(\rho C V)_{c}} \\
\rho_{v h a}^{n+1}=\rho_{v h a}^{n}+\frac{\left(\Delta M_{h a}\right)^{n} \Delta t}{V_{h a}}
\end{gathered}
$$

where,

$$
\begin{aligned}
& \Delta Q_{t}=R_{t}-Q_{t w}-Q_{t h a} \\
& \Delta Q_{h a}=R_{h a}+Q_{e w}+Q_{c w}+Q_{t h a}-Q_{c h a}-Q_{c d h a} \\
& \Delta Q_{c}=R_{c}+Q_{c h a}+Q_{c d h a}+Q_{r w}-Q_{c c}-Q_{r c} \\
& \Delta M_{h a}=A_{w} m_{\text {evap }}-A_{c} m_{\text {cond }}
\end{aligned}
$$

\section{HEAT AND MASS TRANSFER COEFFICIENTS}

\section{(1) Mass transfer coefficients}

a) Evaporative mass transfer coefficient, $\boldsymbol{h}_{e w}$

The heat flux associated with water surface evaporation is given by the product of the heat of vaporization, $L$, and evaporation mass flux, $m_{\text {evap }}$, i.e.,

$$
q_{e w}=L h_{e w}\left(\rho_{v w}-\rho_{v h a}\right)
$$

The value of $h_{e w}$ can be reversely calculated by Equation (5).

\section{b) Condensative mass transfer coefficient, $\boldsymbol{h}_{\text {cdha }}$}

The latent heat due to the condensation on the tubular cover inner surface is given by the product of $L$ and condensation mass flux, $m_{\text {cond }}$, i.e.,

$$
q_{c d h a}=L h_{c d h a}\left(\rho_{v h a}-\rho_{v c}\right)
$$

The value of $h_{c d h a}$ can be reversely calculated by Equation (6). 


\section{(2) Heat transfer coefficients}

\section{a) Convective heat transfer coefficient}

The convective heat flux, $q_{c w}$ between the water surface and the humid air is given by the Newton's law of cooling, i.e.,

$$
q_{c w}=h_{c w}\left(T_{w}-T_{h a}\right)
$$

where, $h_{c w}$ is the convective heat transfer coefficient between water surface and humid air.

$q_{c w}$ is also expressed by the form of sensible heat flux, i.e.,

$$
q_{c w}=v_{a} \rho_{a} C_{p a}\left(T_{w}-T_{h a}\right)
$$

where, $v_{a}$ is the vertical component of air velocity on the water surface $(\mathrm{m} / \mathrm{s}), \rho_{a}$ is the density of air $\left(\mathrm{kg} / \mathrm{m}^{3}\right)$ and $C_{p a}$ is the specific heat of air $\left(\mathrm{J} / \mathrm{kg}^{\circ} \mathrm{C}\right)$. Supposing that $v_{a}$ is equal to the evaporation velocity, $v_{a}$ is given by;

$$
v_{a}=\frac{m_{\text {evap }}}{\rho_{v w}}
$$

Substitution of Equation (5) in Equation (22) yields;

$$
v_{a}=\frac{h_{e w}\left(\rho_{v w}-\rho_{v h a}\right)}{\rho_{v w}}
$$

From Equations (20) and (21), the convective heat transfer coefficient, $h_{c w}$, is expressed as;

$$
h_{c w}=\frac{h_{e w}\left(\rho_{v w}-\rho_{v h a}\right) \rho_{a} C_{p a}}{\rho_{v w}}
$$

The convective heat flux between the humid air and the tubular cover is given by;

$$
q_{\text {cha }}=h_{\text {cha }}\left(T_{h a}-T_{c}\right)
$$

where, $h_{c h a}$ is the convective heat transfer coefficient between humid air and cover.

Supposing that the air velocity component normal to the cover, $v_{a}$, is equal to the condensation velocity, $v_{a}$ is given as follows;

$$
v_{a}=\frac{m_{\text {cond }}}{\rho_{v h a}}
$$

In the same way of evaluating $h_{c w}$, the convective heat transfer coefficient, $h_{\text {cha }}$, is given as;

$$
h_{c h a}=\frac{h_{c d h a}\left(\rho_{v h a}-\rho_{v c}\right) \rho_{a} C_{p a}}{\rho_{v h a}}
$$

The heat flux due to convection between the tubular cover and the surrounding air is calculated by the following equation;

$$
q_{c c}=h_{c c}\left(T_{c}-T_{a}\right)
$$

where, $h_{c c}$ is convective heat transfer coefficient between cover and atmosphere.

The heat transfer coefficient, $h_{c c}$, due to natural (free) convection may be calculated using the empirical relation proposed by Raithby and Hollands ${ }^{12)}$ for a single horizontal cylinder as follows;

$$
N u^{3.3}=N u_{L}^{3.3}+N u_{T}^{3.3}, \quad 10^{-10}<R a<10^{10}
$$

from which,

$$
h_{c c}=\frac{k}{d}\left(N u_{L}^{3.3}+N u_{T}^{3.3}\right)^{\frac{1}{3.3}}
$$

where,

$$
\begin{gathered}
N u_{L}=\frac{2 f}{\ln \left(1+\frac{2 f}{N u_{1}}\right)} \\
N u_{T}=C_{3} R a^{\frac{1}{3}} \\
f=1-\frac{0.13}{\left(N u_{1}\right)^{0.16}} \\
N u_{1}=0.772 C_{1} R a^{\frac{1}{4}}
\end{gathered}
$$

where, $N u$ is the Nusselt number, $k$ is the thermal conductivity $\left(\mathrm{W} / \mathrm{m}^{\circ} \mathrm{C}\right), d$ is the diameter of the TSS (m) and $R a$ is the Rayleigh number. The coefficients, $C_{1}$ and $C_{3}$ are dependent on the Prandtl number ${ }^{12)}$.

The heat transfer coefficient, $h_{c c}$, due to forced convection may be calculated using the empirical relation proposed by Morgan ${ }^{13)}$ for the correlation of cross-flow forced convection from cylinder in air.

$$
N u=D_{2} R e^{n_{1}}
$$

from which,

$$
h_{c c}=D_{2} \frac{k_{a}}{x}\left(\frac{\rho_{a} v_{a} x}{\mu_{a}}\right)^{n_{1}}
$$

where, $k_{a}$ is the thermal conductivity of air $\left(\mathrm{W} / \mathrm{m}^{\circ} \mathrm{C}\right)$, $\rho_{a}$ is the density of air $\left(\mathrm{kg} / \mathrm{m}^{3}\right), v_{a}$ is the air velocity $(\mathrm{m} / \mathrm{s}), \mu_{a}$ is the dynamic viscosity of air $(\mathrm{kg} / \mathrm{m} \cdot \mathrm{s})$ and $x$ is the characteristic dimension i.e., diameter of the TSS (m). The coefficients, $D_{2}$ and $n_{1}$ change with the Reynolds number, $R e^{13)}$.

The energy balance of a trough surrounded with air (or water) can be expressed as;

$$
(\rho C V)_{t} \frac{\partial T_{t}}{\partial t}=-h_{t}\left(T_{t}-T_{a}\right) A_{t}
$$

where, $h_{t}$ is the convective heat transfer coefficient and $A_{t}$ is the contact area between the trough and the air (or water). When the temperature of the air, $T_{a}$ (or water, $T_{w}$ ) is constant, the time variation of $T_{t}$ can be analytically calculated with an initial condition of $T_{t}=T_{t 0}$ for $t=0$.

$$
T_{t}=T_{a}+\left(T_{t 0}-T_{a}\right) \exp \left[-\frac{h_{t} A_{t} t}{(\rho C V)_{t}}\right]
$$

From Equation (34), the trough heat transfer coefficient, $h_{t}$ is given by;

$$
h_{t}=\frac{(\rho C V)_{t}}{A_{t} t} \ln \left(\frac{T_{t 0}-T_{a}}{T_{t}-T_{a}}\right)
$$




\section{b) Radiative heat transfer coefficient}

Radiative heat transfer coefficients in the TSS can be estimated by introducing the concept of view factor. Let us consider the radiative heat transfer between two surfaces $i$ and $j$ with the surface area of $A_{i}$ and $A_{j}$, respectively. The view factor $F_{i j}$ is defined as the fraction of the radiation leaving surface $i$ that strikes surface $j$ directly $\left(F_{i i}=0\right.$ for plane and convex surfaces). The radiosity from the surface $i$ can be expressed as follows;

$$
J_{i}=\varepsilon_{i} \sigma T_{i}^{\prime 4}+\frac{\left(1-\varepsilon_{i}\right)}{A_{i}} \sum_{k=i, j} A_{k} J_{k} F_{k i}
$$

where, $\varepsilon$ is the emssivity, $\sigma$ is the Stefan-Boltzman constant, $6.697 \times 10^{-8}\left(\mathrm{~W} / \mathrm{m}^{20} \mathrm{C}^{4}\right)$ and $T^{\prime}$ is the absolute temperature $\left({ }^{\circ} \mathrm{K}\right)$.

The reciprocity rule can be written as;

$$
A_{i} F_{i j}=A_{j} F_{j i}
$$

The summation rules can be written as;

$$
\begin{aligned}
& F_{i i}+F_{i j}=1 \\
& F_{j i}+F_{j j}=1
\end{aligned}
$$

Using the relation given in Equation (37), Equation (36) can be rewritten as;

$$
J_{i}=\varepsilon_{i} \sigma T_{i}^{\prime 4}+\left(1-\varepsilon_{i}\right) \sum_{k=i, j} J_{k} F_{i k}
$$

The radiative heat flux from the surface $i$ is written as;

$$
q_{i}=\frac{Q_{i}}{A_{i}}=J_{i}-\sum_{k=i, j} J_{k} F_{i k}
$$

The radiative heat transfer flux between the saline water surface and the tubular cover, $q_{r w}$ in general is calculated using Equation (40), i.e.,

$$
q_{r w}=J_{w}-\left(J_{w} F_{w w}+J_{c} F_{w c}\right)
$$

However, $F_{w c}$ becomes 1 from the summation rule, since $F_{w w}$ is 0 because of a plane surface. Therefore, Equation (41) is simplified as;

$$
q_{r w}=J_{w}-J_{c}
$$

Using the reciprocity relations, view factors, $F_{c w}$ and $F_{c c}$, are determined as;

$$
F_{c w}=\frac{A_{w}}{A_{c}} \text { and } F_{c c}=1-\frac{A_{w}}{A_{c}}
$$

Using Equation (39), the radiosity from the water surface, $J_{w}$, and from the tubular cover, $J_{c}$, are written as;

$$
\begin{aligned}
J_{w}= & \varepsilon_{w} \sigma T_{w}^{\prime 4}+\left(1-\varepsilon_{w}\right)\left(J_{c} F_{w c}+J_{w} F_{w w}\right) \\
& =\varepsilon_{w} \sigma T_{w}^{\prime 4}+\left(1-\varepsilon_{w}\right) J_{c} \\
J_{c}= & \varepsilon_{c} \sigma T_{c}^{\prime 4}+\left(1-\varepsilon_{c}\right)\left(J_{w} F_{c w}+J_{c} F_{c c}\right) \\
& =\varepsilon_{c} \sigma T_{c}^{\prime 4}+\left(1-\varepsilon_{c}\right)\left\{J_{w} \frac{A_{w}}{A_{c}}+J_{c}\left(1-\frac{A_{w}}{A_{c}}\right)\right\}
\end{aligned}
$$

Inserting $J_{w}$ and $J_{c}$, solved by Equations (44) and (45), into Equation (42) yields;

$$
q_{r w}=\frac{\sigma\left(T_{w}^{\prime 4}-T_{c}^{\prime 4}\right)}{\frac{1}{\varepsilon_{w}}+\left(\frac{1}{\varepsilon_{c}}-1\right) \frac{A_{w}}{A_{c}}}
$$

where, $\varepsilon_{w}$ and $\varepsilon_{c}$ are the emissivity of the saline water surface and the tubular cover, respectively. Thus, the radiative heat transfer coefficient between the saline water surface and the tubular cover, $h_{r w}$, is,

$$
h_{r w}=\frac{\sigma\left(T_{w}^{\prime 2}+T_{c}^{\prime 2}\right)\left(T_{w}^{\prime}+T_{c}^{\prime}\right)}{\frac{1}{\varepsilon_{w}}+\left(\frac{1}{\varepsilon_{c}}-1\right) \frac{A_{w}}{A_{c}}}
$$

The radiative heat transfer flux between the tubular cover and the sky, $q_{r c}$, is given by;

$$
q_{r c}=\sigma\left(\varepsilon_{c} T_{c}^{\prime 4}-\varepsilon_{s k y} T_{s k y}^{\prime 4}\right)
$$

where, $\varepsilon_{s k y}$ is the emissivity of the sky and is calculated from the vapor density of atmosphere ${ }^{14)}$.

Hence, the radiative heat transfer coefficient between the tubular cover and the sky, $h_{r c}$ becomes

$$
h_{r c}=\frac{\sigma\left(\varepsilon_{c} T_{c}^{\prime 4}-\varepsilon_{s k y} T_{s k y}^{\prime 4}\right)}{\left(T_{c}-T_{a}\right)}
$$

The sky temperature can be approximated by Equation (50) $\left(\right.$ Asano $^{15)}$ );

$$
T_{s k y}^{\prime}=137.5+0.5 T_{a}^{\prime}
$$

\section{EXPERIMENTS}

\section{(1) Indoor experiment}

To identify the heat and mass transfer coefficients $\left(h_{e w}, h_{c d h a}, h_{c w}\right.$ and $\left.h_{c h a}\right)$, indoor experiments were carried out in a thermostatic room to keep steady external surroundings (a constant temperature and relative humidity) at the University of Fukui. The schematic diagram of the experiment is shown in Fig. 2 and a photograph of the experiment is shown in Fig. 3. The equipment consists of a TSS, a solar simulator, two electric balances connected with computers and a data logger. The TSS was comprised of a tubular cover and a semicircular black trough in it. The tubular cover was made of a curled transparent vinyl chloride sheet of $0.5 \mathrm{~mm}$ in thickness and a transparent polyvinyl chloride bottle at both ends. The tubular cover was $0.52 \mathrm{~m}$ in length and with an outside diameter of $0.13 \mathrm{~m}$. The trough was made of vinyl chloride with $1.0 \mathrm{~mm}$ in thickness, $0.1 \mathrm{~m}$ in outside diameter and $0.49 \mathrm{~m}$ in length. Since the attached lid at the end of the tubular cover open easily, the trough can be promptly taken out and inserted back after flushing accumulated salt. The solar simulator had 12 infrared lamps $(125 \mathrm{~W})$ arranged in six rows of two lights each. In this ex- 

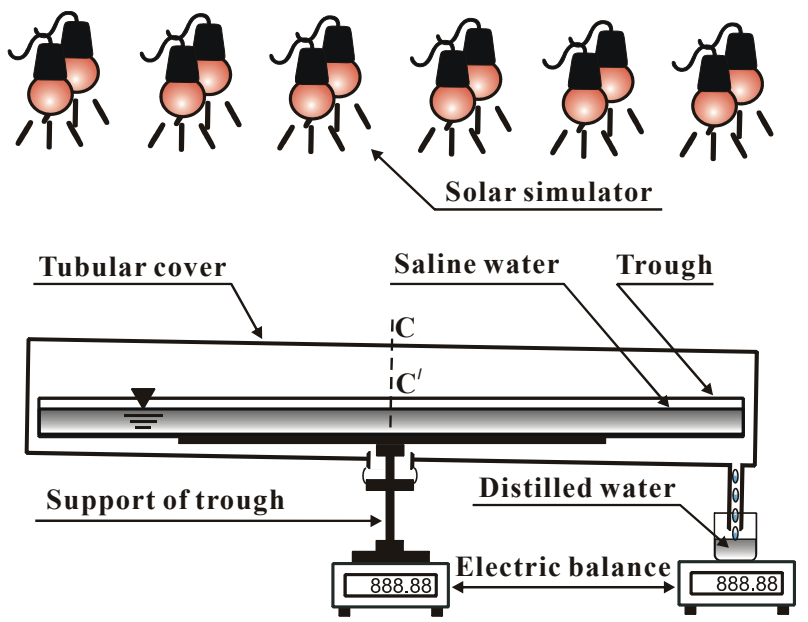

Fig. 2 Schematic diagram of indoor experiment.

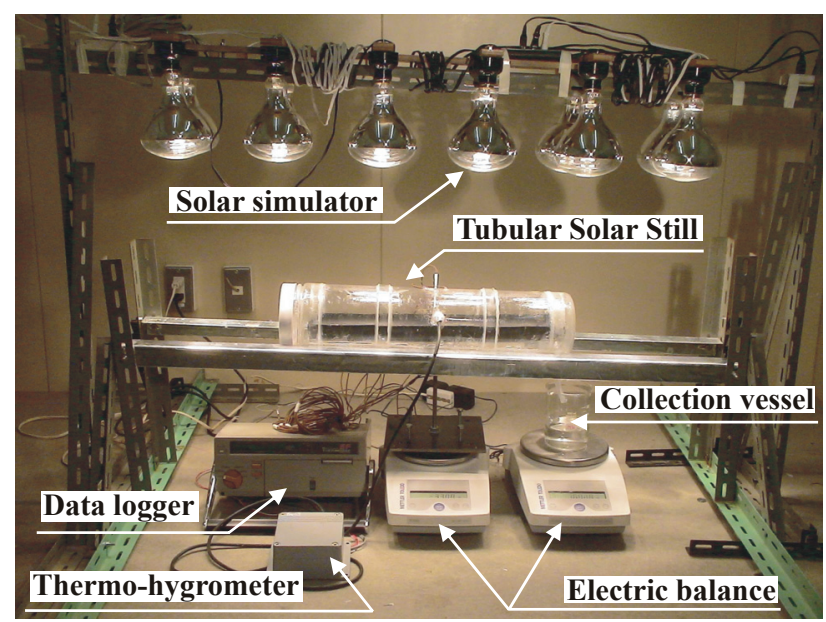

Fig. 3 Photograph of indoor experiment.

periment, the temperatures of saline water $\left(T_{w}\right)$, humid air $\left(T_{h a}\right)$, tubular cover $\left(T_{c}\right)$ and air $\left(T_{a}\right)$, the relative humidities of humid air $\left(R H_{h a}\right)$ and air $\left(R H_{a}\right)$, and radiation flux $\left(R_{s}\right)$ were measured by thermo-couples, thermo-hygrometers and a pyranometer, respectively. These measurements of all were performed in the vertical section at the center of the TSS (section C-C' in Fig. 2). Since the water depth is very small $(1 \sim 2.2 \mathrm{~cm})$, only one thermo-couple was placed in the saline water to measure $T_{w}$. Sixteen thermo-couples were stuck on both the surfaces at eight different points at the same interval along the circumference of the tubular cover surface. The average of the output from these points was adopted as the value of $T_{c}$. One thermo-couple and one thermo-hygrometer were set at a depth of $50 \mathrm{~mm}$ below the top of the tubular cover to measure the temperature and relative humidity of the humid air. The data were automatically recorded to the data logger at one-minute interval. A special experimental technique to measure independently the evaporation in the TSS was developed using a support of the trough on the balance, which was attached without contacting from the

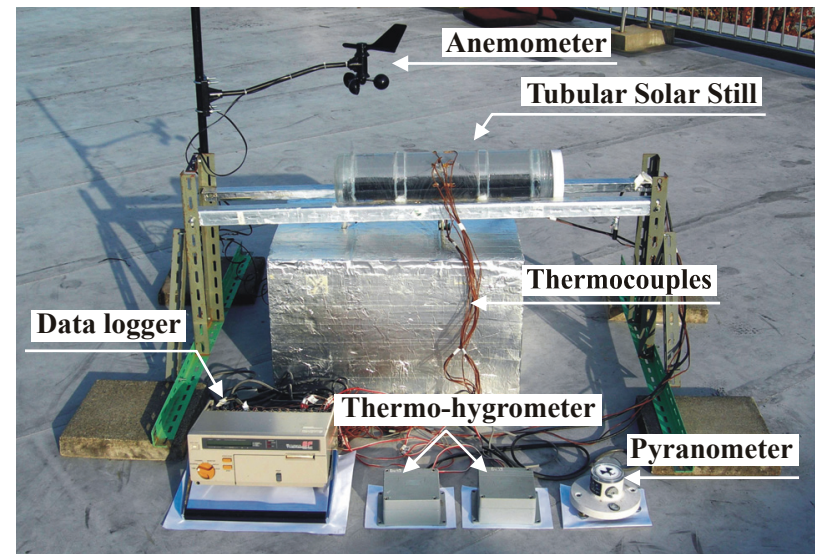

Fig. 4 Photograph of field experiment at Japan.

other compositions of the TSS. The time variation of the evaporation from the saline water surface and of the production from the TSS were also automatically obtained separately and simultaneously using two electric balances with a minimum reading of $0.01 \mathrm{~g}$.

\section{(2) Field experiment}

To support the validity of the proposed model, field experiments were carried out on the roof of Architecture and Civil Engineering building of the University of Fukui, Japan from August to September in 2005. In this study, typical one day data, i.e., September 29, 2005, are presented. Fig. 4 shows a photograph of the field experiment. The TSS explained in Section 4.(1) was used in the field experiment. In addition, an anemometer was used to measure the wind velocity. Temperatures, relative humidities, radiation flux, wind velocity, the evaporation from water surface in the trough and the production from the TSS were recorded at one-minute interval. The two electric balances were put in a box made of styrofoam (heat insulator) covered with aluminum foil so that the noise due to wind, heat and other fluctuations can not be outputted from the electric balances. The experimental result that was carried out in Hamuraniyah, Ras Al Khaimah, UAE namely September 14, 2002 are also used as another field data. In UAE experiment, $1.26 \mathrm{~m}$ long TSS was set and there was no arrangement to measure the evaporation flux. Readers are referred to the reference (Islam et al. ${ }^{16}$ ) for the details of the field experiment in the UAE.

\section{RESULTS AND DISCUSSIONS}

\section{(1) Indoor experiments}

Indoor experiments on the TSS were conducted under fifteen sets of external surroundings shown in Table 2. Details of the experiment are explained in the reference 17). After reaching a steady state, the values of the heat and mass transfer coefficients 
Doboku Gakkai Ronbunshuu B Vol.63 No.2, 108-119, 2007. 4

Table 2 Indoor experimental conditions and observed steady state values for the TSS.

\begin{tabular}{|c|c|c|c|c|c|c|c|c|}
\hline \multirow{3}{*}{$\begin{array}{l}\text { Case } \\
\text { No. }\end{array}$} & \multirow{3}{*}{$\begin{array}{l}\text { Radiative } \\
\text { heat flux } \\
R_{s}\left(\mathrm{~W} / \mathrm{m}^{2}\right)\end{array}$} & \multirow{2}{*}{\multicolumn{2}{|c|}{$\begin{array}{l}\text { Indoor room } \\
\text { conditions }\end{array}$}} & \multicolumn{5}{|c|}{ Observed steady state values } \\
\hline & & & & \multicolumn{3}{|c|}{ Temperature $\left({ }^{\circ} \mathrm{C}\right)$} & \multirow{2}{*}{$\begin{array}{l}\text { Relative } \\
\text { humidity } \\
R H_{h a}(\%)\end{array}$} & \multirow{2}{*}{$\begin{array}{c}\text { Hourly } \\
\text { evaporation flux } \\
\left(\mathrm{kg} / \mathrm{m}^{2} \mathrm{hr}\right)\end{array}$} \\
\hline & & $T_{a}\left({ }^{\circ} \mathrm{C}\right)$ & $R H_{a}(\%)$ & $T_{w}$ & $T_{h a}$ & $T_{c}$ & & \\
\hline 1 & & 35 & & 66.1 & 66.6 & 55.7 & 79 & 0.99 \\
\hline 2 & & 30 & & 64.0 & 64.1 & 52.8 & 78 & 0.97 \\
\hline 3 & 1200 & 25 & 35 & 61.0 & 60.2 & 49.1 & 78 & 0.91 \\
\hline 4 & & 20 & & 58.7 & 58.7 & 44.4 & 73 & 0.88 \\
\hline 5 & & 15 & & 55.0 & 54.0 & 39.2 & 73 & 0.82 \\
\hline 6 & & 35 & & 59.6 & 59.1 & 50.1 & 81 & 0.64 \\
\hline 7 & & 30 & & 56.7 & 56.4 & 48.1 & 82 & 0.60 \\
\hline 8 & 800 & 25 & 35 & 53.4 & 52.2 & 43.3 & 81 & 0.57 \\
\hline 9 & & 20 & & 51.4 & 49.8 & 38.6 & 77 & 0.56 \\
\hline 10 & & 15 & & 48.4 & 45.8 & 33.8 & 75 & 0.51 \\
\hline 11 & & 35 & & 52.1 & 51.0 & 44.9 & 85 & 0.33 \\
\hline 12 & & 30 & & 49.5 & 48.1 & 42.0 & 86 & 0.31 \\
\hline 13 & 500 & 25 & 35 & 45.1 & 43.2 & 36.5 & 86 & 0.29 \\
\hline 14 & & 20 & & 42.1 & 38.1 & 31.7 & 91 & 0.24 \\
\hline 15 & & 15 & & 37.5 & 33.0 & 26.1 & 91 & 0.22 \\
\hline
\end{tabular}

Table 3 Comparison of heat and mass transfer coefficients by the present model and conventional formula.

\begin{tabular}{|c|c|c|c|c|c|c|}
\hline \multirow{3}{*}{$\begin{array}{l}\text { Case } \\
\text { No. }\end{array}$} & \multicolumn{2}{|c|}{ Mass transfer coefficient for TSS $\left(10^{-3} \mathrm{~m} / \mathrm{s}\right)$} & \multicolumn{4}{|c|}{ Convective heat transfer coefficient $\left(10^{-1} \mathrm{~W} / \mathrm{m}^{20} \mathrm{C}\right)$} \\
\hline & \multirow[b]{2}{*}{$h_{\text {cdha }}$} & \multirow[b]{2}{*}{$h_{e w}$} & \multirow[t]{2}{*}{$h_{c h a}$ for TSS } & \multicolumn{3}{|c|}{$h_{c w}$} \\
\hline & & & & $\begin{array}{l}\text { For TSS } \\
\quad(A)\end{array}$ & $\begin{array}{c}\text { Conventional } \\
\text { (B) }\end{array}$ & $\begin{array}{l}\text { Ratio } \\
(B / A)\end{array}$ \\
\hline 1 & 1.71 & 7.94 & 3.85 & 17.21 & 25.54 & 1.48 \\
\hline 2 & 1.78 & 7.90 & 4.12 & 18.47 & 25.59 & 1.39 \\
\hline 3 & 1.91 & 7.66 & 4.74 & 19.77 & 25.40 & 1.29 \\
\hline 4 & 1.87 & 7.22 & 5.30 & 21.29 & 26.33 & 1.24 \\
\hline 5 & 1.92 & 7.05 & 6.21 & 23.56 & 26.45 & 1.12 \\
\hline 6 & 1.69 & 6.79 & 3.42 & 14.83 & 23.60 & 1.59 \\
\hline 7 & 2.03 & 7.04 & 3.59 & 15.89 & 22.34 & 1.41 \\
\hline 8 & 2.05 & 7.02 & 4.22 & 17.67 & 22.77 & 1.29 \\
\hline 9 & 1.71 & 6.08 & 4.77 & 19.28 & 24.35 & 1.26 \\
\hline 10 & 1.97 & 6.24 & 5.59 & 20.41 & 24.83 & 1.22 \\
\hline 11 & 1.71 & 5.37 & 2.46 & 10.97 & 20.47 & 1.87 \\
\hline 12 & 1.76 & 5.36 & 2.68 & 11.73 & 20.35 & 1.73 \\
\hline 13 & 1.59 & 5.57 & 3.16 & 13.43 & 20.80 & 1.55 \\
\hline 14 & 1.42 & 5.14 & 3.32 & 13.46 & 21.64 & 1.61 \\
\hline 15 & 1.44 & 5.22 & 3.98 & 15.34 & 23.57 & 1.54 \\
\hline
\end{tabular}

( $h_{e w}, h_{c d h a}, h_{c w}$ and $\left.h_{c h a}\right)$ were evaluated using Equations (5), (6), (24) and (27) and the results are summarized in Table 3. As the condensation rate was not measured, $h_{c d h a}$ was calculated under the assumption that the condensation flux, $m_{\text {cond }}$, is equal to the evaporation flux, $m_{\text {evap }}$. The convective heat transfer coefficient, $h_{c w}$, for a basin type still was calculated from Equation (1) and was compared with that calculated from Equation (24). It was found that the conventional formula overestimates the value of $h_{c w}$ for the TSS 12 to $87 \%$.

We suppose that the heat and mass transfer coefficients, $h_{e w}, h_{c d h a}, h_{c w}$ and $h_{c h a}$ may be influenced by the convection (air flow) due to the instability of the humid air. The temperature difference between the saline water and the cover, $T_{w}-T_{c}$, may be one of the parameters that represent the degree of instability of the humid air over the saline water surface. Since $T_{w}$ 
is generally higher than $T_{c}$, the humid air may become unstable as the $T_{w}-T_{c}$ increases. Based on this idea, the relations between the mass transfer coefficients, $h_{e w}$ and $h_{c d h a}$, and the temperature difference, $T_{w}-T_{c}$, are shown in Fig. 5(a) and (b), respectively. The values of $h_{e w}$ and $h_{c d h a}$ are proportional to $T_{w}-T_{c}$ and may be expressed as;

$$
\begin{gathered}
h_{e w}=5.86 \times 10^{-3}+6.50 \times 10^{-5}\left(T_{w}-T_{c}\right) \\
h_{c d h a}=1.55 \times 10^{-3}+1.97 \times 10^{-5}\left(T_{w}-T_{c}\right)
\end{gathered}
$$

Fig. 6(a) and (b) show the relations between the convective heat transfer coefficients, $h_{c w}$ and $h_{c h a}$, and the temperature difference, $T_{w}-T_{c}$. Both $h_{c w}$ and $h_{\text {cha }}$ are proportional to $T_{w}-T_{c}$ and may be given by the following equations, respectively.

$$
\begin{aligned}
& h_{c w}=25.32 \times 10^{-2}+13.11 \times 10^{-2}\left(T_{w}-T_{c}\right) \\
& h_{c h a}=-3.35 \times 10^{-2}+4.04 \times 10^{-2}\left(T_{w}-T_{c}\right)
\end{aligned}
$$

The heat transfer coefficients for the trough-humid air, $h_{\text {tha }}$ and the trough-water, $h_{t w}$ were 12.0 and 67.8 $\mathrm{W} / \mathrm{m}^{20} \mathrm{C}$, respectively, from our experiment ${ }^{15)} . h_{t w}$ is 5.7 times greater than $h_{\text {tha }}$.

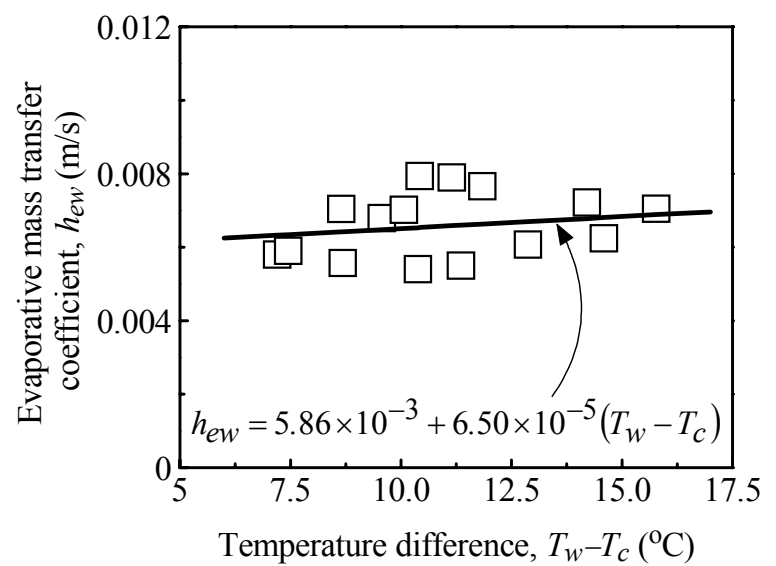

a) Evaporative mass transfer coefficient, $h_{e w}$

\section{(2) Field experiments}

Two typical one-day data, of September 29, 2005 (in Fukui, Japan) and of September 14, 2002 (in Hamuraniyah, UAE) were used in this paper.

Fig. 7(a) and (b) show the observed diurnal variations of hourly evaporation and production per unit saline water surface area, $m_{e h}$ and $m_{p h}$, solar radiation flux, $R_{s}$, relative humidity of humid air, $R H_{h a}$, temperatures $T_{w}, T_{h a}, T_{c}$ and $T_{a}$, in Fukui, and in UAE, respectively. Regardless of Fukui or UAE, $m_{p h}, R_{s}, T_{w}, T_{h a}, T_{c}$ and $T_{a}$ rose rapidly after sunrise (approximately 6:00) and peaked between 12:00 to 13:00 before declining gradually. $R H_{h a}$ was remarkably below $100 \%$ in the daytime (minimum $54 \%$ and $62 \%$ for Fukui and UAE, respectively) but almost $100 \%$ during the night. A further important point of Fig. 7 is the relation between $m_{e h}$ and $m_{p h}$ obtained in Fukui. $m_{e h}$ was observed from 7:00 (after sunrise), while $m_{p h}$ was recorded from 9:00. There exists a time lag between evaporation and production. Furthermore, it is found that $m_{e h}$ is greater than $m_{p h}$ until 13:00 but this relation becomes a contrary after 14:00.

Fig. 5 Relation between mass transfer coefficients and temperature difference, $T_{w}-T_{c}$.

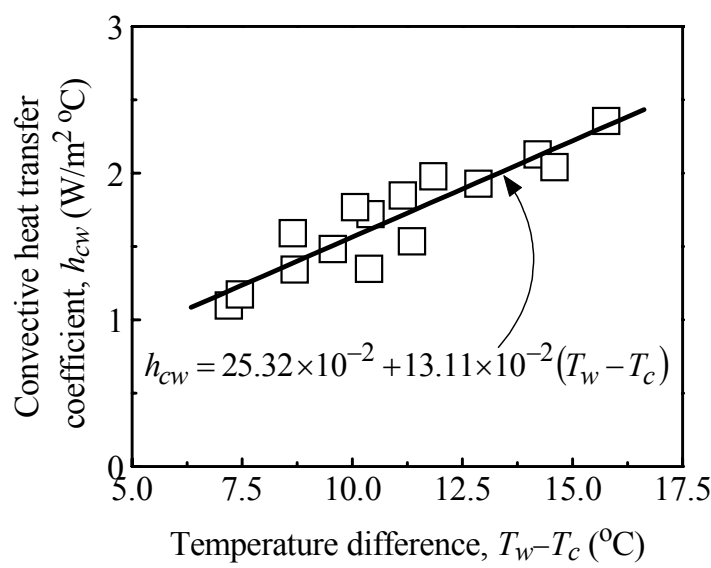

a) Convective heat transfer coefficient, $h_{c w}$

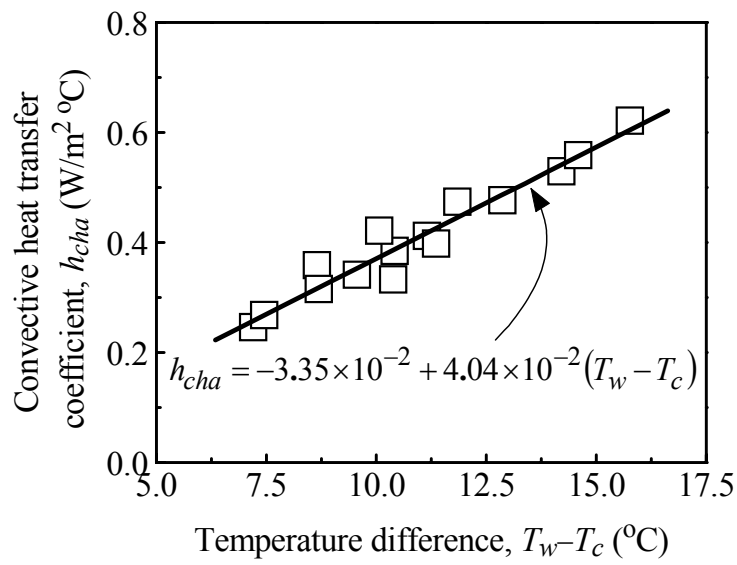

b) Convective heat transfer coefficient, $h_{c h a}$

Fig. 6 Relation between convective heat transfer coefficients and temperature difference, $T_{w}-T_{c}$. 


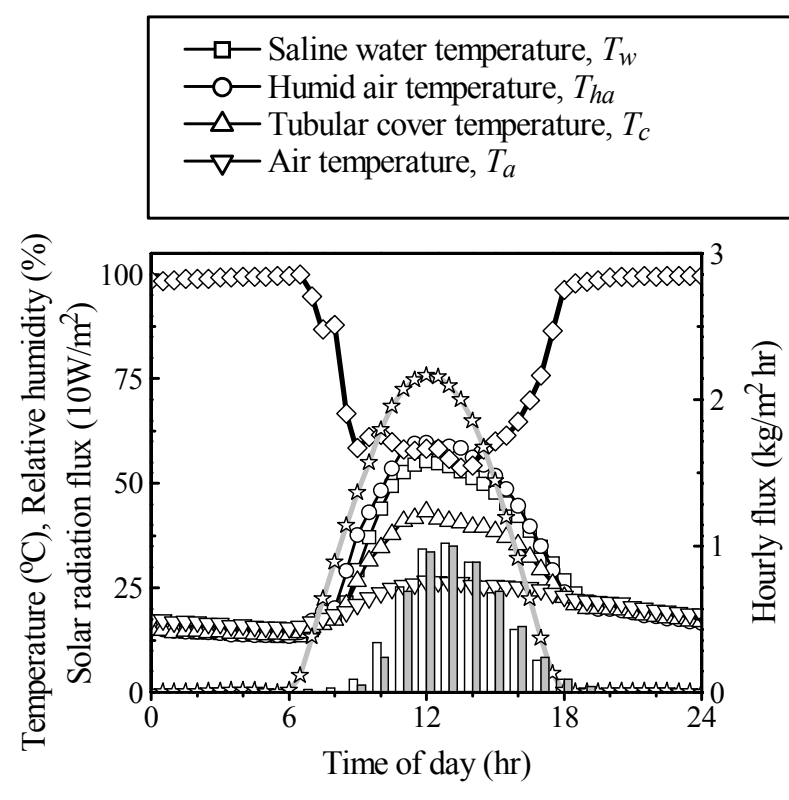

a) September 29, 2005 in Fukui, Japan
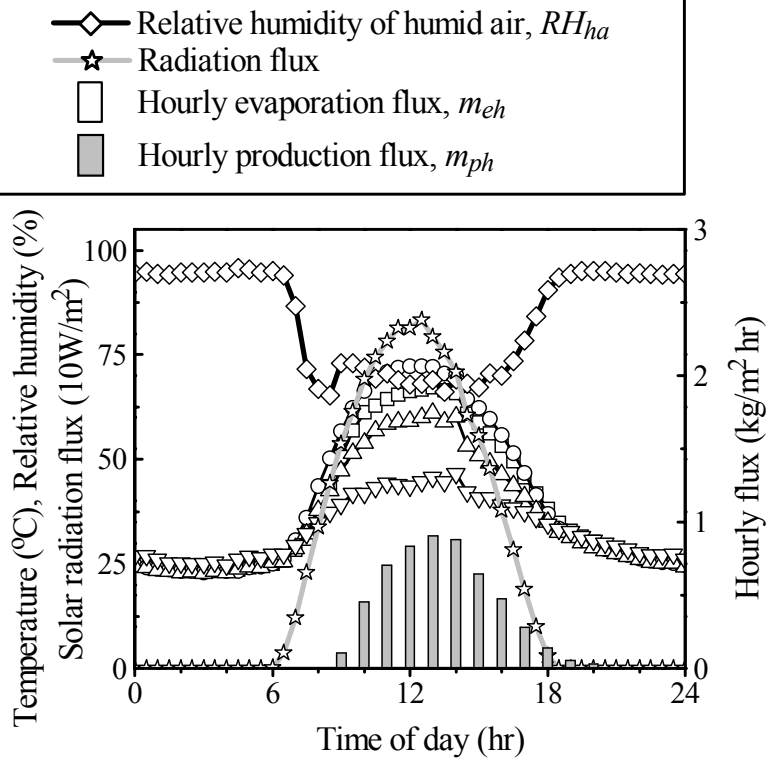

b) September 14, 2002 in Hamuraniyah, UAE

Fig.7 Diurnal variations of temperatures, relative humidity, radiation flux and evaporation and production fluxes in the TSS.

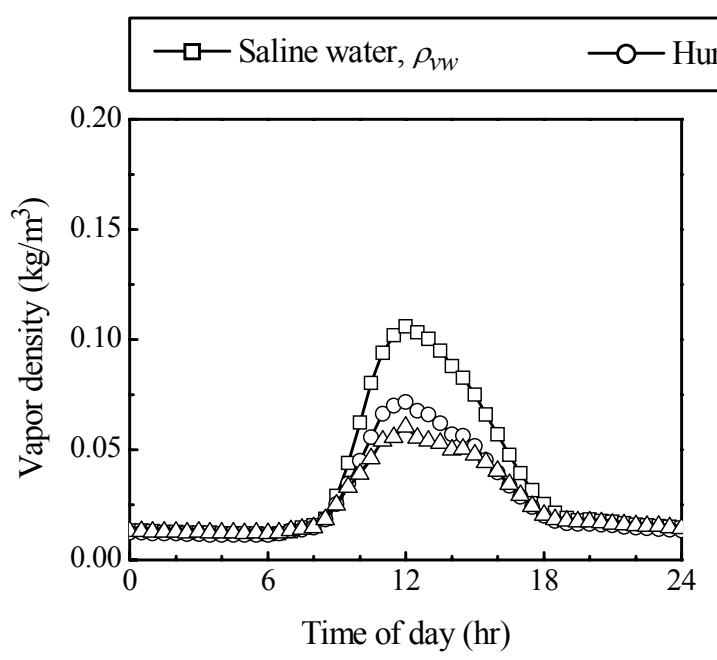

a) September 29, 2005 in Fukui, Japan

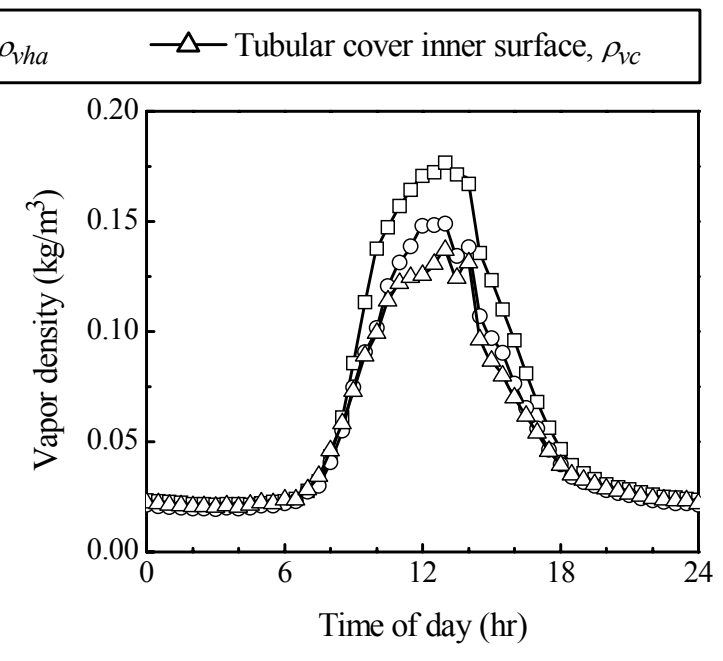

b) September 14, 2002 in Hamuraniyah, UAE

Fig.8 Diurnal variations of observed vapor densities in the TSS.

Fig. 8(a) and (b) show the diurnal variations of three vapor densities, $\rho_{v w}, \rho_{v c}$ and $\rho_{v h a}$ obtained in Fukui, Japan and in Hamuraniyah, UAE, respectively. Every vapor density started increasing after sunrise, peaked between 12:00 to 13:00, then decreased gradually and became almost equal during the night. From these figures, it is also found that the condensation condition, $\rho_{v h \mathrm{a}}>\rho_{v c}$, was satisfied at 9:00 in both cases. The values of $\rho_{v w}, \rho_{v h a}$ and $\rho_{v c}$ were high in order once the condensation took place.

\section{(3) Numerical results}

The time interval $\Delta t$ was taken as 0.01 second for the calculation of temperatures, hourly evaporation and condensation fluxes from the model. The reduction in the volume and surface area of the saline water associated with the evaporation was taken account in the model. The design parameters used in the model is as: $\alpha_{t}=1.0 ; \alpha_{c}=0.15 ; \alpha_{h a}=0.0 ; \alpha_{w}=$ $0.50 ; a l_{t}=0.05 ; a l_{c}=0.05(0.15$ for UAE $) ; a l_{w}=$ $0.05 ; \varepsilon_{w}=0.96 ; \varepsilon_{c}=0.85$. The increase in $a l_{c}$ for UAE is attributed to the reduction of the transmissivity of tubular cover due to the ultra violet ray.

The temperatures, $T_{w}, T_{h a}$ and $T_{c}$ at each time step were calculated from Equations (13), (15) and (16), respectively. Knowing the values of $T_{w}$ and $T_{c}, \rho_{v w}$, and $\rho_{v c}$, are estimated. Since $\rho_{v h a}$, is calculated using 
Equation (17), the $R H_{h a}$, is easily obtained. The evaporation and the condensation fluxes at each time step are calculated using Equations (5) and (6), respectively.

Fig. 9(a) and (b) show the comparison of the calculated temperatures, hourly evaporation and condensation fluxes with the observed ones in $\mathrm{Fu}-$ kui, Japan and in Hamuraniyah, UAE, respectively. The observed evaporation (Fukui only) or production fluxes are almost the same as the calculated evaporation and condensation fluxes. The time variations of the calculated temperatures have also good agreement with observed ones.

Fig. 10(a) and (b) show the time variations of the calculated vapor densities $\left(\rho_{v w}, \rho_{v c}\right.$ and $\left.\rho_{v h a}\right)$ and $R H_{h a}$ with the observed ones in Fukui and in UAE, respectively. Calculated profiles are almost the same as the observed ones. It can be recognized from $\rho_{v h a}$ and Equation (4), that the evaporation from the saline water surface, $M_{\text {evap }}$, is greater than the condensation on the inner surface of the tubular cover, $M_{\text {cond }}$, until the time (12:00 to 13:00) when the maximum $\rho_{v h a}$ appears. On the contrary, $M_{\text {cond }}$ is greater than $M_{\text {evap }}$ for the period of $d \rho_{\text {vha }} / d t<0$ (after 14:00). It is of interest that the time period of $m_{e h}>m_{p h}$ and $m_{e h}<m_{p h}$ as shown in Fig. 7(a) is the same as the time period of $M_{\text {evap }}>M_{\text {cond }}$ and $M_{e-}$ ${ }_{\text {vap }}<M_{\text {cond }}$ in Fig. 10(a), respectively. Taking account of the time lag between the evaporation and condensation in the TSS, it may be better to regard the condensation flux as the hourly production rather than the evaporation flux. From Figs. 9 and 10, however, it is seen that the proposed model can reproduce the experimental results well. Practically, therefore, either of the evaporation or the condensation flux calculated by the present model can be used to predict the production flux.

\section{CONCLUSIONS}

In this study, attempts were made to provide a group of complete heat and mass transfer correlations, and to propose a new heat and mass transfer model for the Tubular Solar Still by taking account of thermal properties of the humid air inside the still. The proposed model consists of the heat balance equations of the saline water, the trough, the humid air and the tubular cover and the mass balance equations of the saline water and the water vapor in the humid air. Fifteen sets of indoor experiment on the TSS were conducted to evaluate the production performance and the heat and mass transfer coefficients. Field experiments were also conducted to evaluate the validity of the model.

The main conclusions drawn from the present study are as follows:

i) The heat and mass transfer coefficients, $h_{c h a}, h_{c w}$, $h_{c d h a}$ and $h_{e w}$ can be expressed as functions of the temperature difference between the saline water and the cover.

ii) The conventional formula (Equation (1)) overestimates $h_{c w}$ for the TSS.

iii) The proposed model is capable to reproduce the observed humid air properties (temperature, vapor density and relative humidity) and condensation flux besides the saline water temperature, tubular cover temperature, trough temperature and evaporation flux. Hence, the distillation productivity of TSS can be evaluated by the proposed heat and mass transfer model.

The Future direction of this study will be as follows:

i) Extended indoor experiments using different length scales are expected to obtain dimensionless heat and mass transfer coefficients ex-

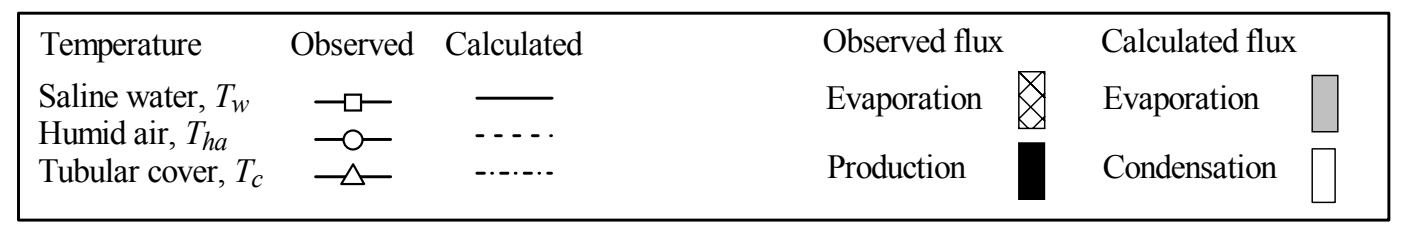

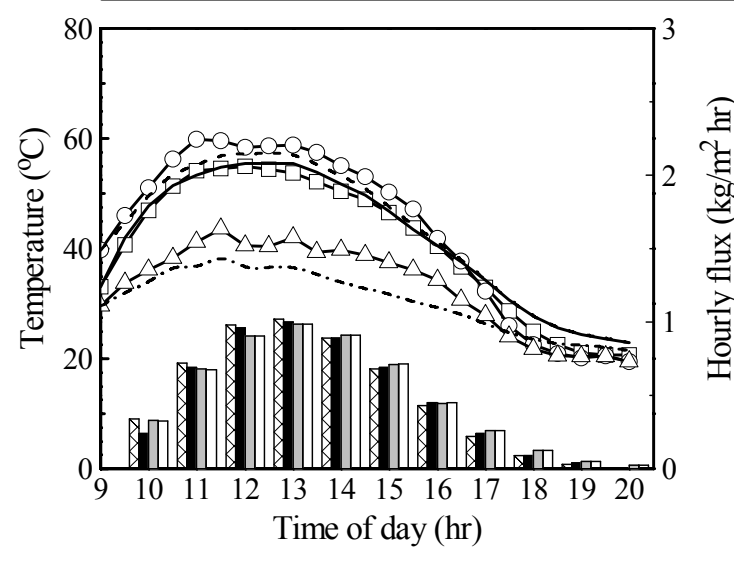

a) September 29, 2005 in Fukui, Japan

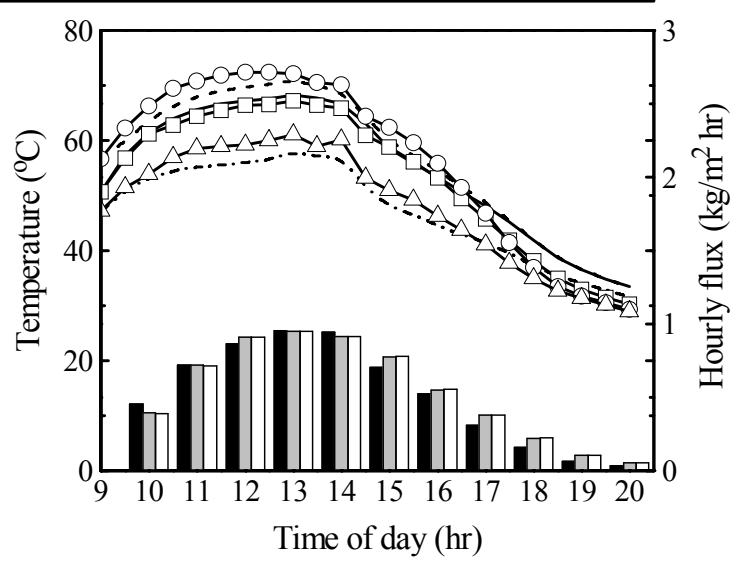

b) September 14, 2002 in Hamuraniyah, UAE

Fig. 9 Comparison of the calculated temperatures, evaporation and condensation fluxes with the observed values. 


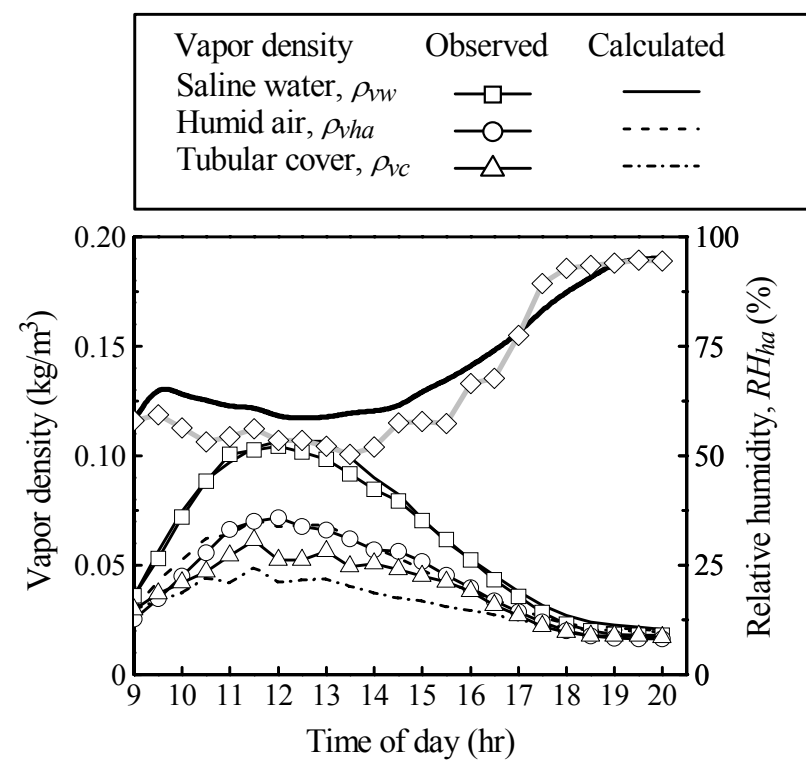

a) September 29, 2005 in Fukui, Japan
Relative humidity Calculated

of humid air, $\mathrm{RH}_{\mathrm{h}}$

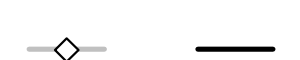

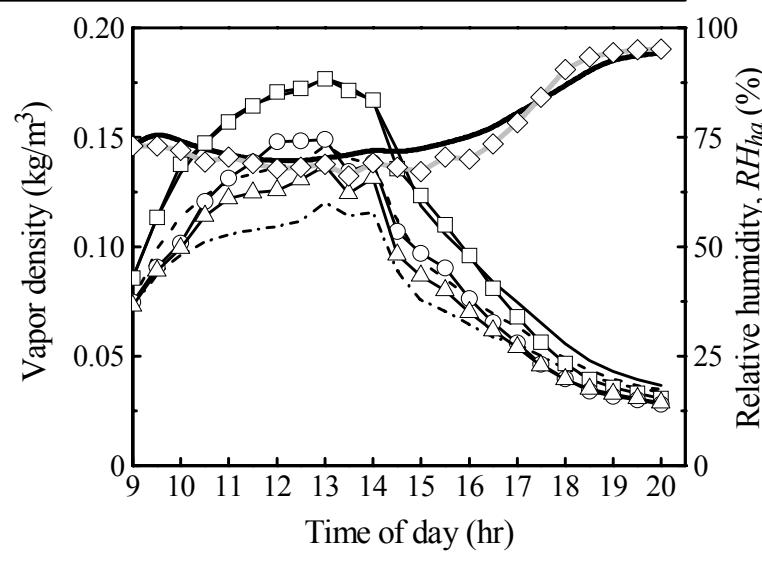

b) September 14, 2002 in Hamuraniyah, UAE

Fig. 10 Comparison of the calculated vapor densities and relative humidity, $R H_{h a}$ with the observed values.

pressed in terms of dimensionless parameters.

ii) It is desirable to improve the experimental technique to measure the condensation rate directly and evaluate the condensative mass transfer coefficient more preciously.

iii) It is also desirable to design a TSS that satisfies commercial purposes.

\section{REFERENCES}

1) Chaibi, M. T. : Analysis by simulation of a solar still integrated in a greenhouse roof, Desalination, Vol. 128, pp. 123-138, 2000.

2) Clark, J. A. : The steady-state performance of a solar still, Solar Energy, Vol. 44, No. 1, pp. 43-49, 1990.

3) Cooper, P. I. : Digital simulation of transient solar still processes, Solar Energy, Vol. 12, pp. 313-331, 1969.

4) Dunkle, R. V. : Solar Water Distillation: The roof type still and a multiple effect diffusion still, Proc. Int. Heat Transfer, ASME, Part V, University of Colorado, pp. 895-902, 1961.

5) Hongfei, Z., Xiaoyan, Z., Jing, Z. and Yuyuan, W. : A group of improved heat and mass transfer correlations in solar stills, Energy Conversion \& Management, Vol. 43, pp. 2469-2478, 2002.

6) Malik, M. A. S., Tiwari, G. N., Kumar, A. and Sodha, M. S. : Solar Distillation: A practical study of a wide range of stills and their optimum design, construction and performance, Pergamon Press, Oxford, England, pp. 11-13, 1982.

7) Shawaqfeh, A. T. and Farid, M. M. : New development in the theory of heat and mass transfer in solar stills, Solar Energy, Vol. 55, No. 6, pp. 527-535, 1995.

8) Kumar, A. and Anand, J. D. : Modelling and performance of a tubular multiwick solar still, Energy, Vol. 17, No. 11, pp. 1067-1071, 1992.
9) Tiwari, G. N. and Kumar, A. : Nocturnal water production by tubular solar stills using waste heat to preheat brine, $D e$ salination, Vol. 69, pp. 309-318, 1988.

10) Nagai, N., Takeuchi, M., Masuda, S., Yamagata, J., Fukuhara, T. and Takano, Y. : Heat transfer modeling and field test on basin-type solar distillation device, Proc. of the International Desalination Association, Bahrain, CD-ROM, Bah03-072, 2002.

11) Islam, K. M. S. and Fukuhara, T. : Heat and mass transfer in tubular solar still under steady condition, Annual Journal of Hydraulic Engineering, JSCE, Vol. 49, pp. 727-732, 2005.

12) Raithby, G. D. and Hollands, K. G. T. : Handbook of heat transfer fundamentals, Eds., Rohsenow, W., Hartnett, J. and Ganic, E., $2^{\text {nd }}$ edition, McGraw Hill, pp. 6-1-6-94, 1985.

13) Morgan, V. T. : The overall convective heat transfer from smooth circular cylinder, Advances in heat transfer, Eds., Irvine, J. T. F. and Hernett, J. P., Academic, New York, pp. 199-264, 1975.

14) Brutsaert, W. : On a derivable formula for long-wave radiation from clear skies, Water Resources Research, Vol. 11, pp. 742-744, 1975.

15) Asano, F. : Production model of tubular solar still, steady state model, Master's thesis, Department of Architecture and Civil Engineering, University of Fukui, Japan, 2004.

16) Islam, K. M. S., Fukuhara, T., Asano, F. and Mutawa, H. A. A. : Productivity of the tubular solar still in the United Arab Emirates, Proc. of MTERM international conference, pp. 367-372, 2005.

17) Islam, K. M. S., Fukuhara, T. and Asano, F. : Experimental study on heat and moisture transfer in tubular solar still, Proc. of IDA world congress on desalination and water reuse, CD-ROM, SP06-136, 2005.

(Received January 25, 2006) 